\title{
Monetary policy, structural break, and the monetary transmission mechanism in Thailand ${ }^{*}$
}

\author{
Heiko Hesse $^{\dagger}$ \\ World Bank
}

\begin{abstract}
The paper studies monetary policy and the monetary transmission mechanism in Thailand in light of the Asian Crisis in 1997. Existing studies that adopt structural VAR approaches do not give a clear and agreed-upon view how monetary shocks are transmitted to the Thai economy that is subject to structural breaks. This study explicitly models a pre-crisis and post-crisis cointegrated VAR model. This analysis supports the arguments of Corbett and Vines (1999) as well as Phongpaichit and Baker (2002) that the trinity of open capital markets, pegged exchange rate regime and monetary policy autonomy is inconsistent in the pre-crisis period. In contrast, the model points to an effective monetary policy in the post-crisis period. Further, the author analyzes the common driving trends of the model.
\end{abstract}

Keywords: Thailand; Monetary Policy; Monetary Transmission Mechanism; Asian Financial Crisis; Cointegration; Common Trends JEL classification: C32; E41; E58; F41

World Bank Policy Research Working Paper 4248, June 2007

The Policy Research Working Paper Series disseminates the findings of work in progress to encourage the exchange of ideas about development issues. An objective of the series is to get the findings out quickly, even if the presentations are less than fully polished. The papers carry the names of the authors and should be cited accordingly. The findings, interpretations, and conclusions expressed in this paper are entirely those of the authors. They do not necessarily represent the view of the World Bank, its Executive Directors, or the countries they represent. Policy Research Working Papers are available online at http://econ.worldbank.org.

*I am very grateful to Bent Nielsen for his help and suggestions during the process of the paper. I am also thankful to Heino Bohn-Nielsen, Soren Johansen, Katerina Juselius and Anders Rahbek for providing excellent support during a summer school on cointegrated VAR methods and comments on an earlier draft at the University of Copenhagen. In addition, my thanks are due to Ronald Babula, Roy Bailey, Steve Bond, Chris Bowdler, Julia Giese, David Hendry, Patrick Honohan, Takamitsu Kurita, Roland Meeks, John Muellbauer, Jonas Stulz, David Vines, Ilknur Zer, as well as seminar participants at the U.S. International Trade Commission, Bank of Thailand, Chulalongkorn and Thammasat University for helpful comments. † hhesse@worldbank.org. 


\section{Introduction}

Thailand has undergone some rapid changes in its monetary policy framework in the last decade. The collapse of its exchange rate, the baht, in 1997 led to the abandonment of the pegged exchange rate regime and movement towards a monetary targeting regime implemented through the IMF program. Following the end of the IMF program an inflation targeting regime was introduced in 2000 where targeting of domestic money supply was replaced by an explicit inflation objective.

Given these regime shifts and structural break of the Asian Crisis, existing work on the monetary transmission mechanism in Thailand has been unsatisfactory. Many studies such as Patrawimolpon et al (2001), Fung (2002), Disyatat and Vongsinsirikul (2003) and Hirunraengchok (2004) build structural VAR models in order to analyse the responses of Thai economic variables to monetary policy shocks. These studies often face econometric deficiencies insofar as they do not deal adequately with the structural break of the Asian Crisis, lack the property of a well-specified model or do not account for the nonstationarity of their macroeconomic data. The bottomline is that many of such studies using the structural VAR approach to the Thai economy fail to render a clear and agreed-upon view of how monetary policy shocks are transmitted to that economy.

In our study, we propose a different way of studying the monetary transmission mechanism in Thailand based on the cointegrated VAR model. We first estimate an unrestricted VAR model and then determine the relevant long-run cointegrating relationships. Following an identification of the cointegrating vectors, we are able to identify the short-run structure of the cointegrated VAR model and use the model to illuminate the patterns with which monetary policy shocks are potentially affecting key macroeconomic variables in the Thai economy. We make use of the difference between common stochastic trends that have permanent effects on the system variables and shocks to endogenous variables that are only transitory in character.

A major challenge to the analysis is that Thailand has been seriously hit by the Asian Crisis in 1997. This will make the specification of a model a very difficult task because the relevant variables of the model exhibit jump-like behaviour around the crisis. We anticipate that the underlying stochastic process in the Thai economy has changed following the crisis. Similar to Patrawimolpon et al (2001) and Fung (2002), we implement a subsample- based analysis, that, is, a pre- crisis and post-crisis model but with the novel approach to rationalize and synthesize the differences between both models.

Our results for the pre-crisis model reveal that unlike many studies on Thailand, we cannot recoup an interest rate policy function and that the central bank had difficulty controlling money. These findings support Corbett and Vines (1999) and Phongpaichit and Baker (2002) who state that Thai monetary policy was immobilized in the period before the devaluation of the baht in 1997 . They put forward the Mundell-Fleming type argument that the trinity of open capital markets, pegged exchange rate regime and monetary policy autonomy is inconsistent.

Regarding the Thai monetary transmission mechanism we find that monetary shocks have permanent positive effects on inflation. We do not obtain a Phillips curve relationship for the precrisis model but inflation appears to be a monetary phenomenon and caused by excessive liquidity in the economy. In addition, interest rate shocks have consistently negative effects on output. This could be due to a possible financial accelerator explanation (Bernanke et al, 1996). 
For the post-crisis model, we observe that the cointegrating rank of the model increases. Monetary policy becomes an effective tool to steer the economy by virtue of the fact that the exchange rate becomes flexible, and we are able to obtain an interest rate policy function. We also find a type of money demand function in which money supply is related to the output gap and the exchange rate which could proxy as an opportunity cost.

We organize the paper as follows: Section 2 gives a brief literature overview whereas section 3 provides an overview of the Thai economy as well as the data used in our study. In section 4, we analyse the long-run relationships in a cointegrated VAR model using a pre-crisis and post-crisis subsample. Section 5 provides evidence for the hypothesis that a full sample model that includes the Asian Crisis is unstable. Following the long-run analysis we focus on the short-run dynamics of the model by identifying the common stochastic driving forces (section 6). Finally, section 7 concludes with possible extensions to our work.

\section{Literature Overview}

In light of the regime shift and structural break of the Asian Crisis, there has been some recent attempts by economists such as Hirunraengchok (2004), Disyatat and Vongsinsirikul (2003), Fung (2002), Song (2002) and Patrawimolpon et al (2001) to model exogenous Thai monetary policy shocks and the Thai monetary transmission mechanisms.

Specifically, Patrawimolpon et al (2001) adopt the methodology of Bernanke and Mihov (1998) to the Thai economy. ${ }^{1}$ Based on the Choleski decomposition numerous alternative orderings are adopted depending on whether the central bank targets the short term interest rate or the money supply. Because of the structural break of the Asian crisis in July 1997, two different monthly models are estimated, one for the pre-crisis period 1987:1 - 1997:6 and another for the post-crisis economy in 1997:7 - 2000:4. Results of the impulse responses depend on the ordering of the variables. For instance, in the pre-crisis model and the specific ordering where the central bank targets the interest rate, we obtain the perverse effect of a positive relationship between the money supply (M1) and 14- days repurchase rate. If the central bank controls the money supply instead, a negative relationship ensues for the pre-crisis period. The results of the post-crisis period are in general unreliable due to the very short sample.

The methodology and reasoning of Patrawimolpon et al (2001) suffer from some weaknesses. The authors do not deal with the issue of nonstationarity. In other words, most variables are probably I(1) so we require either first differencing or cointegration techniques to ensure conventional statistical inference. Also, the identification of their monetary policy shocks based on the Choleski decomposition is not unique, and results crucially depends on the ordering of the variables so reliable inference from their impulse responses is very hard to obtain. Impulse responses of their post-crisis models differ fundamentally from the pre-crisis model which provides evidence that the structural break in 1997 shifted the underlying stochastic process of the economy.

\footnotetext{
${ }^{1}$ Bernanke and Mihov (1998) build a structural VAR model to investigate whether short term interest rates decrease with monetary expansion, the so-called liquidity effect, and whether there is no real effect of monetary policy in the long run (long run neutrality of money).
} 
In a related vein, Fung (2002) investigates monetary policy shocks across seven East Asian countries including Thailand. His pre-crisis model yields more sensible impulse responses than the initial full sample model that included the Asian Crisis. The results of Patrawimolpon et al (2001) and Fung (2002), by dividing their analysis into two subsamples, indicate that structural VAR models that do not explicitly account for the Asian Crisis are inherently flawed in their identification of monetary policy shocks and their policy implications from impulse response analysis.

A recent influential study of the Thai monetary transmission mechanism was conducted by Disyatat and Vongsinsirikul (2003). ${ }^{2}$ What differentiates the study of Disyatat and Vongsinsirikul (2003) from the other structural VAR models about Thailand is that they explicitly analyze the various channels through which monetary policy changes are transmitted to the economy, that is, the interest rate, balance sheet, bank lending, exchange rate and asset price channels. ${ }^{3}$ For this purpose, they extend a basic monetary type model which includes GDP, consumer prices and the 14-days repurchase rate with each of the relevant variables thought to constitute a particular transmission channel. In most cases, the exogenize their unrestricted VAR with the exchange rate in order to control for the effects of the Asian Crisis. Their quarterly estimation sample is 1993:12001:4. Their results are fairly robust to alternative causal orderings, and they test for parameter stability using a different monthly model. Some critical remarks are directed to their short sample of roughly 40 observations so potential degrees of freedom problems might occur. In addition, they estimate their VAR equations in levels which raises the question of nonstationarity and unit root issues. Lastly, inferences from robustness and specification tests that are conducted on a different monthly model in contrast to the employed quarterly model are invalid because sample periods and the underlying stochastic process are potentially different. Chow test results are not independent of the sample length. ${ }^{4}$

The bottomline of the structural VAR approach to the Thai economy is that the existing studies do not give a clear and agreed-upon view how monetary policy shocks are transmitted to the economy. Even though the identification schemes vary, most studies face some common deficiencies. These are more from an econometric perspective and point to issues such as 'how well-specified is the statistical model?,' 'how to deal with structural breaks such as the Asian Crisis?,' 'what about nonstationarity?,' 'how reasonable are arbitrary causal orderings if Choleski decompositions are employed?' and finally, 'how sensible is it to assume specific forms of money demand functions and macroeconomic relationships in the Thai economy a priori?' The last point is very important because it directs the attention to the primary goal of this paper to conduct a cointegration analysis of monetary policy and the monetary transmission mechanism in Thailand.

A few economic studies with an interest in the Thai money demand functions have explicitly used the Johansen procedure to obtain long-run relationships between Thai economic variables.

\footnotetext{
${ }^{2}$ They follow the approach by Bayoumi and Morsink (2001) who investigated the Japanese transmission mechanism in a structural VAR model with the conventional Choleski decomposition. A related study who essentially follows the same approach as Disyatat and Vongsinsirikul (2003) is Baqir (2002).

${ }^{3}$ See Mishkin (1995) and Christiano et al (1999) for an overview of the monetary transmission channels and its literature.

${ }^{4}$ Alternative approaches that model monetary policy shocks as well as the Thai transmission mechanisms and predominantly employ non-recursiveness assumptions are by Hirunraengchok (2004) and Song (2002). Whereas Hirunraengchok (2004) estimates the model in first differences, Song (2002) assumes that the underlying VAR process is covariance stationary.
} 
Among them, Chowdhury (1997) finds in a cointegrating VAR that includes M1, output, prices, exchange rate and a measure of the foreign interest rate, two cointegrating vectors. Further, Masih and Masih (1996) reach similar results for a different sample period and frequency of observations. Hence, we can embed long-run relationships into the analysis of Thai monetary policy and the monetary transmission mechanism without having to assume specific forms of money demand functions and other macroeconomic relationships such as a monetary policy rule or inflation adjustment equation. This approach is promising because once we have identified the cointegrating vectors, we can fix them at their estimated values and treat them as predetermined stationary variables in the ensuing identification of the short run structure. In addition, the cointegration methodology will allow us to explicitly account for the permanent and transitory driving forces in the model by modelling the common stochastic trends in order to get some insights into the Thai monetary transmission mechanism. Lastly, the deficiencies of the above-mentioned structural VARs to the Thai economy offer room for improvement such as use of dummy variables, sample period selection, adequate model specification and invariance to the structural break by subsampling.

In terms of our modelling strategy, similar cointegrated VAR studies have been undertaken by Juselius (1996) and Beyer (1999) for the case of Germany. For example, Juselius (1996) obtains two different monetary policy regimes for her sample period. In a related vein, Doornik et al (1996), Pesaran and Smith (1998) and Juselius (2007) provide the underlying theoretical framework for our study of the Thai monetary transmission mechanism.

\section{Overview of the Thai Economy and Data}

In general, the monetary policy framework in Thailand in the last twenty years can be characterized by a basket approach in the pegged exchange rate regime from 1984- June 1997, a monetary targeting regime from July 1997- May 2000 and an inflation targeting regime until today.

Phongpaichit and Baker (2002) provide a thorough overview of the macroeconomic developments in Thailand over the last two decades. Following the abandonment of Thailand's import substitution strategy in the mid-1980s, Thailand's macroeconomic framework was characterized by a fixed exchange rate regime as the nominal anchor and tight fiscal policy to pave the way for the export boom.

Many international companies from East Asia set up production facilities in Thailand especially in electrical and automotive industries. The export boom resulted in a tight labour market, increased foreign competition and a negative current account in the early 1990s. The problem was that at the same time, Thailand liberalized its financial markets so that Thailand's inherent problems were overshadowed insofar as its economy continued to grow, partly due to high volumes of bank lending. During this period monetary policy was immobilized through the exchange rate peg and the financial liberalization.

A year before the crisis, Thailand suffered an export slowdown that resulted from decreasing demand from Japan, accelerated competition from China and higher labor costs. Warr (1998) provides a taxonomy of the boom and bust arguing that the investment boom in combination 
with a consumption boom made the export sector very uncompetitive through cost increases, and the exchange rate could not adjust. Furthermore, domestic financial intermediaries increased their exposure to foreign lending which arose from favorable interest rates abroad so this posed future asset and liability problems to them. ${ }^{5}$

From another perspective, Kasajima and Lewis (2001) reason that the Thai nominal exchange rate has been overvalued to the real effective exchange rate, the latter which observed a real depreciation for most of the early 1990s. In general, Thailand's current account deficit reached a historic high level in the second quarter of 1996. Note that we do not explicitly attempt to explain the causes for the Thai currency and financial crisis. ${ }^{6}$

Based on the negative external shocks, the Bank of Thailand decided to devalue the baht in July 1997 which drastically increased the exposure of Thai companies to debt denominated in foreign currencies. In that August, the Thai central bank ordered over 40 financial companies to suspend their operation. Rating agencies such as S\&P reduced its sovereign risk rating for Thailand to BBB, the minimum investment grade, in September. By November the same year, both the finance and prime minister had resigned from their post. Alongside the turmoil on the domestic financial markets the authorities further deregulated the financial sector by allowing investors to increase their share ownership of existing financial institutions (November, 1997) and by dismantling currency controls (January, 1998). By the beginning of 1998, the rating of various financial institutions reached junk status, and interest rates soared to historical high levels. In 2006, Thailand still faces problems in terms of non-performing loans in a weakly functioning banking system as well as high government debt levels.

The dataset consists of monthly observations from January 1989 up to December 2004. All variables except the US price level are not seasonally adjusted. The following variables are mainly used in the analysis:

\begin{tabular}{lll}
\hline \hline Variable & Details & Source \\
\hline$R M 1$ & Log real money $M 1=L M 1-L C P I$ & IFS \\
$L M P I$ & Log manufacturing production index & IFS \\
$L C P I$ & Log Consumer Price Index (Thailand) & IFS \\
$R P$ & Repurchase rate, 14 days /1200 & IFS \\
$L E X C H$ & Log nominal exchange rate (Baht/US Dollar) & IFS \\
$L C P I U$ & Log Consumer Price Index (USA) & LOU \\
$P P P$ & Log PPP relation $=L C P I-L C P I U-L E X C H$ & Own Calculations \\
$L L E N D I N G$ & Log bank Lending & IFS \\
\hline \multicolumn{2}{l}{ Source: IMF International Financial Statistics (IFS), Labour Office in the USA (LOU) } \\
\hline \multicolumn{2}{l}{ Totes: 'L' $L^{\prime}$ log, ' $D$ 'D $D$} \\
\hline
\end{tabular}

\footnotetext{
${ }^{5}$ Similarly, according to Warr and Vines (2003), Thailand's investment boom and bust mainly contributed to the increased vulnerability of the economy.

${ }^{6}$ There is a huge literature on modelling the Asian currency and financial crisis. See Krugman (1999), Masson (1999), Agenor et al (1999), Irwin and Vines (2003) amongst others. Krugman (1999) attempts to explain the Asian crisis from deteriorating firms' balance sheets and moral harzard problems whereas Masson (1999) postulates a story in which contagion was the predominant factor. In contrast, Irwin and Vines (2003) combine various strands of the so-called 'third generation models' into a coherent framework that involves investment collapse, moral hazard problems, and multiple equilibria. Finally, Agenor at al (1999) provide a full conceptual, empirical and theoretical account of the crisis.
} 

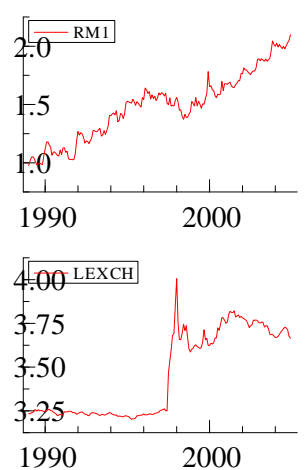

$0=2$
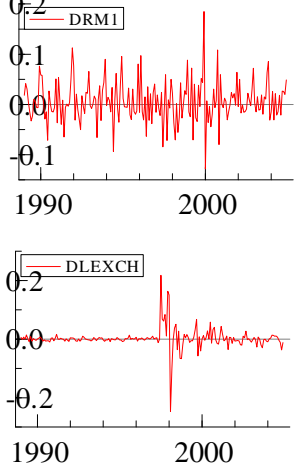
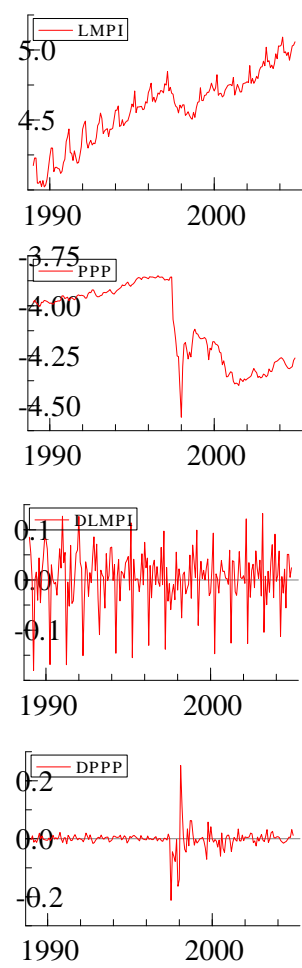
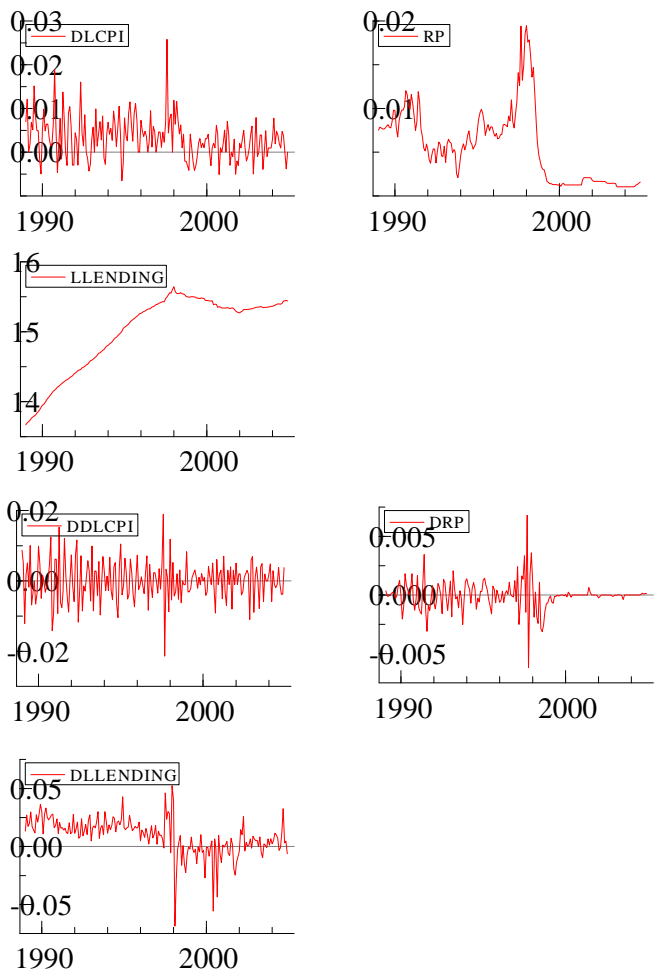

Figure 1: Log levels and first differences of the variables, 1989:01- 2004:12

Thailand faces some data problems because often monthly macroeconomic variables are only available for a short sample period, usually starting at the end of the 1980s. For example, most studies on monetary policy and the monetary transmission mechanism in Thailand have to rely on quarterly data because measures of real GDP are not available on a monthly basis. For instance, Disyatat and Vongsinsirikul (2003) only employ 40 observations in their study which makes their results unreliable due to limited degrees of freedoms in their unrestricted VAR model estimation. To avoid or minimize these problems, we chose to use the Thai manufacturing production index (MPI) as a proxy for GDP, and we acknowledge the limitations in accuracy of this choice. ${ }^{7}$ The 14-days repurchase rate $(\mathrm{RP})$ is a measure of the short-term interest rate. ${ }^{8}$

Figure 1 presents the $(\log )$ levels and first differences of the relevant system variables for the full sample period.

We assume that long-run price homogeneity holds, that is, $(D L M 1-D L C P I) \sim I(0)$ so that money growth and inflation are cointegrated and move together in the long-run. Given long-run homogeneity, we know that $(L M 1-L C P I) \sim I(1)$. Here, we follow the treatment of Juselius (2007) who also assumes long-run price homogeneity. Including nominal money growth and prices into the cointegrated VAR model could potentially complicate the analysis because of possible I(2)

\footnotetext{
${ }^{7}$ As a consistency check, we calculated the correlation coefficient between quarterly GDP from its first available date and the analogue MPI. The correlation coefficient from the first quarter of 1993 to the fourth quarter of 2004 is around 0.94. Even though, the comparison does not cover the first four years in our sample, it can serve as a indication that the MPI is a good proxy for GDP fluctuations.

${ }^{8}$ To make further analysis comparable with logarithmic monthly changes, RP is divided by 1200 , to allow for a monthly measure.
} 
behavior. It is quite common in the cointegrated VAR literature with focus on monetary policy to implement the nominal-to-real transformation. ${ }^{9}$

\section{Cointegration Analysis}

In the following, we estimate a pre-crisis and post-crisis model:

$$
\triangle x_{t}=\alpha \beta^{*^{\prime}}\left(\begin{array}{c}
x_{t-1} \\
t
\end{array}\right)+\Gamma_{1} \triangle x_{t-1}+\mu_{0}+\Phi_{t} D_{t}+\epsilon_{t}
$$

where the vector of endogenous variables $x_{t} \sim I(1), \beta^{*^{\prime}}=(\beta, \rho)^{\prime}, \Gamma_{1}$ is the matrix of short-run coefficients, and the error terms $\epsilon_{t}$ are assumed to be white noise with $\epsilon_{t} \sim N(0, \Omega)$. The coefficient matrix $\Phi_{t}$ contains the permanent as well as the seasonal dummies, and the trend is given by $t$. We can think of the columns of $\beta$ as the number of cointegrating vectors, and $\alpha$ is defined as the adjustment vector, measuring how strong the cointegrating relationships feed back into each individual equation in the above vector error correction form.

The pre-crisis model will contain the sample period from January 1989 up to the beginning of the Asian Crisis in June 1997 whereas the post-crisis model comprises the period 1998:1- 2004:12. Note that we omit six months within the crisis period in order to avoid the high degree of volatility of the relevant endogenous variables. The variables included are real money, output, monthly inflation, interest rates and the nominal exchange rate, that is, $x=\{R M 1, L M P I, D L C P I, R P, L E X C H\} .{ }^{10}$

The rationale for choosing some of the variables is as follows: As defined before, $M 1$ denotes narrow money which includes currency in circulation and demand deposits with the central bank and private banks. By using real money $R M 1$, we implicitly impose homogeneity of degree one between nominal money and domestic prices. The Thai central bank operates the repurchase market which is the predominant channel through which it conducts open market operations by injecting or draining reserves to the banking system. Therefore, the 14-days repurchase rate $R P$ is a key interest rate that qualifies as a proxy of measuring the opportunity costs of holding money. Various authors such as Disyatat and Vongsinsirikul (2003) and Fung (2002) also adopt RP as the relevant interest rate. Lastly, we employ the monthly inflation rate $D L C P I$ instead of the yearly rate because the volatility of the annual rate by far exceeds the monthly rate especially after the Asian Crisis.

\subsection{Pre-Crisis Model}

The pre-crisis model contains some impulse dummies that we will outline in the following. An impulse dummy takes the value one in the concerned month and the value zero before and after the specified period. An impulse dummy for October 1990 is included into the model for the reason that in September 1990 Thailand was involved in a serious corruption scandal that saw the dismissal of twenty ministers. This was just four months before a coup overthrew the government and the prime minister was dismissed. We believe that it had some impact on inflation.

\footnotetext{
${ }^{9}$ We also test whether the key findings hold without the nominal-to-real transformation.

${ }^{10} \mathrm{~A}$ restricted trend will be used in the estimation to avoid a quadratic trend if the trend was unrestricted. In addition, an unrestricted constant will be utilized.
} 
In addition, we incorporate an impulse dummy for June 1991. From a historical perspective this dummy can be explained as follows: In 1991:4, Thailand was subject to some financial market liberalization. The government announced the loosening of foreign exchange rate controls, and it introduced a value added tax system that took effect in the following January 1992. The dummy is able to account for the volatile movement of the interest rates during this period. We also recall that our dataset is not seasonally adjusted so that we include 11 seasonal dummies into our model.

The estimation results based on a lag length of two indicate that the seasonal dummies are highly significant for the output variable LMPI in almost every month and for real money RM1 in some months. ${ }^{11}$ Similarly, both impulse dummies are highly significant.

In order to obtain a well-specified model, it is essential to test for potential autocorrelation, normality or ARCH effects. These misspecification tests do not show any problem. Furthermore, we want to perform some parameter constancy tests in order to investigate the degree of fluctuations of the endogenous variables over the sample period. A base model with 50 observations is estimated and the parameters are recursively estimated for the remaining sample period. There are no significant problems in these Chow tests.

The determination of the cointegrating rank $r$, that is, the number of relations that can be classified as equilibrium errors from steady-state, is a very delicate choice, and often requires not only statistical judgment but also sound economic reasoning. Table 2 gives the result of the trace test (see Johansen 1988, 1995) which indicates $r=2 .{ }^{12}$

\begin{tabular}{cccccc}
\hline \hline p-r & r & Eig.Value & Trace & Frac95 & P-Value \\
\hline 5 & 0 & 0.49 & 147.02 & 88.55 & 0.00 \\
4 & 1 & 0.31 & 78.81 & 63.66 & 0.00 \\
3 & 2 & 0.23 & 41.14 & 42.77 & 0.07 \\
2 & 3 & 0.09 & 15.02 & 25.73 & 0.58 \\
1 & 4 & 0.06 & 5.72 & 12.45 & 0.51 \\
\multicolumn{5}{r}{ Table 2: }
\end{tabular}

Auxiliary cointegration tests such as an inspection of the characteristic roots of the companion matrix or the trace test without dummy variables confirm our choice. ${ }^{13}$ Also, we could not find any I(2) trends in our model. Finally, some selected recursive tests were estimated in order to examine the overall degree of parameter constancy in the rank-restricted $(r=2)$ cointegrated VAR model. ${ }^{14}$ Evidence is generally insufficient to reject the null hypothesis of parameter constancy over the estimation period.

We continue our empirical analysis with some simple hypothesis testing on the adjustment parameters $\alpha$ and the pushing forces $\beta$. The relevant results are reported in table 3 for $r=2$.

\footnotetext{
${ }^{11}$ The optimal lag length of the unrestricted model based on likelihood ratio tests and the information criteria is $k=1$. Since the first lag only allows for adjustment towards long-run equilibrium, and the second lag allows for short-run effects within the statistical model, we choose $k=2$.

${ }^{12}$ The critical values of the trace test also account for the restricted trend because the choice of rank depends on whether a trend is included in the cointegration space or not.

${ }^{13}$ The choice of the rank should be independent from the inclusion of permanent and seasonal dummies.

${ }^{14}$ For instance, the recursively calculated fluctuation test of the eigenvalues measures the stability of the eigenvalues for each of the two cointegrating relationships.
} 


\begin{tabular}{|c|c|c|c|}
\hline & LR exclusion & Stationarity & Weak exogeneity \\
\hline & Statistic is $\chi^{2}(2)$ & Statistic is $\chi^{2}(4)$ & Statistic is $\chi^{2}(2)$ \\
\hline RM1 & $8.49 \quad(0.01)$ & $33.55(0.00)$ & $6.12 \quad(0.05)$ \\
\hline LMPI & $(0.01)$ & $35.48(0.00)$ & $12.01(0.00)$ \\
\hline DLCPI & $41.94(0.00)$ & $7.40 \quad(0.12)$ & $41.15(0.00)$ \\
\hline $\mathrm{RP}$ & $0.70 \quad(0.70)$ & $22.65(0.00)$ & $2.74 \quad(0.25)$ \\
\hline LEXCH & $(0.02)$ & $31.15(0.00)$ & $(0.74)$ \\
\hline Trend & $10.87(0.00)$ & & \\
\hline
\end{tabular}

Firstly, we conduct the null hypothesis that any given endogenous variable can be excluded from the two steady state relationships. We cannot reject long-run exclusion for $R P$ with a p-value of 0.70 so the interest rate should not enter the cointegrating space. We have to be cautious because from the $\Pi$ matrix the interest rate is significantly equilibrium correcting and also $R P$ might be slightly collinear with output and the exchange rate so potentially biasing the results. The test for long-run exclusion further suggests that real money $R M 1$, output $L M P I$, the monthly inflation rate $D L C P I$ and the exchange rate $L E X C H$ are potentially 'endogenous' variables so this is a guidance in subsequently identifying the two cointegrating relationships.

Secondly, a test for stationarity without including the restricted trend is negative for all system variables except the inflation rate $D L C P I$ with a p-value of 0.12 . Thirdly, we conduct some weak exogeneity tests. Weak exogeneity refers to the situation when a variable can influence the steadystate path of the remaining variables in the system but is completely invariant to the equilibrium errors of these variables. In other words, there is no level feedback to the weakly exogenous variables. The results of the tests indicate that the null hypothesis of weak exogeneity cannot be rejected for $R M 1, R P$ and $L E X C H$. In addition, a joint weak exogeneity test is accepted with a p-value of 0.05 .

There is no level feedback to money, and shocks to money are permanent and not transitory. It appears that the Bank of Thailand had difficulty in controlling money in the pre-crisis period. Hence, we can observe scenarios where the money supply is determined by market forces, and the central bank had only limited scope to control inflation. Such a conclusion is tentative and subject to our model validity. ${ }^{15}$

Besides real money, both the cumulated residuals of the interest rate and the exchange rate are common stochastic trends in our system. The result for the exchange rate is not surprising because it has been fixed for the complete sample period. Hence, the exchange rate is not determined endogenously within the system. By the fact that the interest rate is weakly exogenous, we are unable to recoup any type of interest rate policy function such as a Taylor rule type. These results are robust to replacing the 14-days repurchase rate with the alternative interest rate measure of the money market rate. ${ }^{16}$

\footnotetext{
${ }^{15}$ For instance, our model is a small scale macroeconomic model so does not fully replicate real world phenomena. The results are robust to using M2 instead of narrow money M1. But the findings could not be invariant to a very broad measure such as M4, even though Thai researchers predominantly adopt either the M1 or M2 measure. Also, the fact that $R M 1$ is weakly exogenous does not imply that nominal money is weakly exogenous and uncontrollable. But we also estimate a model with nominal money instead and do find that nominal money is weakly exogenous, therefore providing some robustness for our above argumentation.

${ }^{16}$ Both the 14-days repurchase rate and the money market rate have a very high correlation of over 0.90 over the
} 
The above findings lend support to the conventional Mundell-Fleming model which postulates that the trinity of open capital markets, pegged exchange rate regime and monetary policy autonomy is inconsistent. Because monetary policy is primarily directed to maintaining the peg between the Thai Baht and the US dollars, monetary policy effects are potentially undermined and immobilized.

For example, according to Corbett and Vines (1999), the inconsisteny of this trinity made the Thai economy vulnerable to external shocks in the pre-crisis period. The financial liberalization of Thai capital markets in the late 1980s and early 1990s led to a inflow of foreign capital. The Thai central bank attempted to moderate the resulting economic boom by increasing interest rates in 1993-4. It argued that a pegged exchange rate regime and an open capital account were compatible because of Thailand's export strength and its high reserves.

But the peg of the Thai Baht undermined the slow down of the economy because domestic companies especially financial intermediaries took advantage of the interest rate differential between domestic and foreign interest rates by increasing their foreign lending. ${ }^{17}$ More foreign lending, of course, increased the companies' exposure to unhedged foreign debt and made the Thai economy more vulnerable.

Phongpaichit and Baker (2002) share the same argument as Corbett and Vines (1999). They reason that the central bank's monetary tightening in 1993-4 was counter-productive to cool down the Thai economy because banks could just borrow abroad. In contrast, before the liberalization of Thai financial markets and a closed capital account, monetary policy was effective in raising/decreasing interest rates to steer the economy through its business cycles.

Overall, our model suggests that the central bank had difficulty in controlling the money supply because even though it managed to generate credit constraints in the Thai economy, Thai banks could easily borrow on international financial markets. Therefore, the creation of inside money undermined the effectiveness of monetary policy. The fact that both real money and the interest rate are weakly exogenous, supports the above reasoning. In the following, we will identify the two cointegrating relationships (table 4 ).

\footnotetext{
sample period. So the robustness of the results is not surprising.

${ }^{17}$ Through the exchange rate peg, domestic companies had in facto an implicit financial guarantee of their foreign lending. The financial guarantee decreased the risk premium on investment which subsequently was feeding back into the continuation of the investment boom. (see Corbett and Vines, 1999)
} 


\begin{tabular}{|c|c|c|c|c|c|c|}
\hline & RM1 & LMPI & DLCPI & $\mathrm{RP}$ & LEXCH & TREND \\
\hline$\beta_{1}$ & $\begin{array}{l}-0.02 \\
-3.27]\end{array}$ & $\begin{array}{l}0.02 \\
{[3.27]}\end{array}$ & 1 & 0 & 0 & 0 \\
\hline$\beta_{2}$ & 0 & 1 & 0 & $\begin{array}{l}5.18 \\
{[2.72]} \\
\end{array}$ & $\begin{array}{l}0.54 \\
{[1.63]} \\
\end{array}$ & $\begin{array}{c}-0.0066 \\
{[-46.41]} \\
\end{array}$ \\
\hline \multirow{2}{*}{\multicolumn{2}{|c|}{ DRM1 }} & \multicolumn{2}{|c|}{$\alpha_{1}$} & \multicolumn{3}{|c|}{$\alpha_{2}$} \\
\hline & & \multicolumn{2}{|c|}{$\begin{array}{l}-0.52 \\
{[-0.56]}\end{array}$} & \multicolumn{3}{|c|}{$\begin{array}{l}-0.18 \\
{[-1.66]}\end{array}$} \\
\hline \multicolumn{2}{|c|}{ DLMPI } & \multicolumn{2}{|c|}{$\begin{array}{l}-0.78 \\
{[-0.78]}\end{array}$} & \multicolumn{3}{|c|}{$\begin{array}{l}-0.47 \\
{[-4.18]}\end{array}$} \\
\hline \multicolumn{2}{|c|}{ DDLCPI } & \multicolumn{2}{|c|}{$\begin{array}{l}-1.10 \\
{[-8.87]}\end{array}$} & \multicolumn{3}{|c|}{$\begin{array}{l}0.02 \\
{[1.75]}\end{array}$} \\
\hline \multicolumn{2}{|c|}{ DRP } & \multicolumn{2}{|c|}{$\begin{array}{l}-0.05 \\
{[-1.21]}\end{array}$} & \multicolumn{3}{|c|}{$\begin{array}{c}-0.003 \\
{[-0.59]}\end{array}$} \\
\hline \multicolumn{2}{|c|}{ DLEXCH } & \multicolumn{2}{|c|}{$\begin{array}{l}0.06 \\
{[0.30]}\end{array}$} & \multicolumn{3}{|c|}{$\begin{array}{l}0.05 \\
{[2.43]}\end{array}$} \\
\hline \multicolumn{2}{|c|}{ Table 4: } & \multicolumn{2}{|c|}{ An overidentifyin } & \multicolumn{3}{|c|}{ un structure [t-v } \\
\hline
\end{tabular}

The first cointegration relationship corresponds to an inflation adjustment equation in which inflation is reacting to the inverse velocity of money. Formally,

$$
D L C P I=0.02 \times(R M 1-L M P I)
$$

In other words, real money in excess of output causes inflationary tendencies even though the effect is weak. Looking at the adjustment coefficients $\alpha$, we observe that the inflation rate is highly reacting to the inflation adjustment equation, as we would expect. Therefore, it appears that the principal component to determine inflation is inverse velocity, and this is consistent with a monetary phenomenon interpretation. Conditional on the inverse velocity, there appears to be no separate Phillips Curve effect because fluctuations in excess money are a good explanation for the trajectory of inflation. This result is analogous to Bhanthumnavin (2002) who does not find any Phillips Curve in Thailand for the pre-crisis period.

In the second long-run relationship, we obtain a reduced form IS-type equation of the following form:

$$
(L M P I-0.0066 \times \text { trend })=-5.18 \times R P-0.54 \times L E X C H
$$

The left-hand side characterizes the output gap which has the conventional negative relationship to the interest rate and is negatively reacting to the exchange rate. A possible explanation for the negative interest rate effect could be that the domestic interest rate proxies foreign interest rate movements. The intuition is that if there was no independent monetary policy, the domestic rate is tight to the foreign rate. Shocks to the foreign interest rates will influence the domestic rate which eventually feed back into output.

Another potential reason could be the financial accelerator argument developed by Bernanke, Gertler and Gilchrist (1996). In their theoretical framework, higher domestic interest rates will put constraints on the balance sheets of manufacturing firms from deteriorating credit conditions. Higher agency costs will lead financial intermediaries to increase loan rates which subsequently feeds back into lower output. 
A possible explanation for the exchange rate effect is that while exchange rate depreciation might have improved the real exchange rate and promoted output, with the high levels of short-term foreign debt, such an effect is far outweighed by short-term foreign debt costs with depreciation. The nominal exchange rate could thus proxy for the contractionary effect on output of a huge increase in foreign debt repayments. But we note from the t-value of the exchange rate that the effect is not very strong, and any exchange rate depreciation would have been rather minimal in the pre-crisis period.

\subsection{Post-Crisis Model}

We recall that we omit the crisis months from 1997:7-1997:12. It precludes the high volatility during the crisis months from distorting the new cointegrating relations. The exchange rate highly depreciates, monthly inflation jumps up due to immediate higher import costs, real money and output sharply decline and the interest rate level soars to very high levels in the months following the crisis. In such a scenario with the according political instability in Thailand, it is sensible to leave out the crisis months for the post-crisis subsample analysis.

For the purpose of obtaining a well-specified model, we aim at detecting potential outliers in our sample and dummy them out. For instance, the volatility in the beginning of 1998 potentially permeates upon the dynamics of the interest rate. Therefore, similar to the pre-crisis model, we impose impulse dummy variables. Impulse dummies for March, June and July 1998 attempt to capture very volatile movements in the interest rate. Furthermore, impulse dummies for December 1999, October 2000 and November 2003 primarily correspond to abrupt movements in real money. For example, real money RM1 expanded in December 1999 at the same time when the Thai Baht appreciated very strongly which had a positive effect on Thai equities.

The findings of the same unrestricted VAR model as in the pre-crisis period demonstrate that the seasonal dummies succeed in capturing seasonal elements in both real money and output. As anticipated, the impulse dummies for the interest rate fluctuations and real money movements are significant. All the endogenous variables are highly equilibrium-correcting to themselves which suggests that both money and interest rates appear to be endogenously determined within the model in the post-crisis period unlike the pre-crisis.

Autocorrelation and $\mathrm{ARCH}$ effects are no problems in our model specification. Normality cannot be rejected for all except the interest rate. This arises from its high volatility in the initial post-crisis period. Interest rates reach historical heights in the early 1998s before subsequently falling to very permanent low levels. Hence, a test of vector normality is rejected with a p-value of 0.01 . The post-crisis model is stable based on the Chow tests.

Table 5 gives the trace test for our well-specified model which suggests $r=3$. 


\begin{tabular}{cccccc}
\hline \hline p-r & r & Eig.Value & Trace & Frac95 & P-Value \\
\hline 5 & 0 & 0.79 & 287.15 & 88.55 & 0.00 \\
4 & 1 & 0.61 & 157.88 & 63.66 & 0.00 \\
3 & 2 & 0.49 & 79.74 & 42.77 & 0.00 \\
2 & 3 & 0.21 & 25.05 & 25.73 & 0.06 \\
1 & 4 & 0.07 & 6.17 & 12.45 & 0.45 \\
\hline \multicolumn{5}{c}{ Table 5: Trace Test for Post-Crisis Model } \\
\hline
\end{tabular}

It is reasonable to expect more than two cointegrating relationships in the post-crisis period because the model should converge to a stable path if we assume that it has been out-of-equilibrium prior to the crisis. Therefore, we immediately observe that the underlying stochastic process in the Thai economy has altered following the Asian Crisis. We also could not find any $\mathrm{I}(2)$ trends in our model, and recursive estimation of the cointegrated VAR model provides evidence for parameter stability.

No variable can be excluded from the cointegrating space, and stationarity tests indicate that except the interest rate, no variable is stationary by itself and would form a cointegrating vector. Note that the result for RP is slightly ambiguous because of the p-value under the null (0.10).

From the tests for weak exogeneity, the output proxy qualifies as a common stochastic trend whereas the null hypothesis of weak exogeneity is strongly rejected for real money, inflation rate and the interest rate. Whereas output was determined endogenously in the pre-crisis model, it now becomes significantly weakly exogenous. One potential reason might be that output fluctuations cannot be explained by interest rates and the exchange rate because of the severity of the initial post-crisis depression.

Conversely, both real money and the interest rate become highly endogenous after the Asian crisis. The abandonment of the exchange rate peg contributed to the new results. The aforementioned impossible trinity of exchange rate peg, open capital markets and monetary policy control has been broken. We also note also that the exchange rate was highly weakly exogenous in the pre-crisis model but the fact that the exchange rate does not pass the null hypothesis of weak exogeneity in the post-crisis period suggests an alteration of the exchange rate regime.

The preferred choice for the identification of the three $\beta$-vectors is presented in table 6 . Note that we already imposed weak exogeneity of output on the adjustment factors $\alpha$. The identification of the $\alpha$ - and $\beta$-vectors is accepted with a p-value of 0.86 . 


\begin{tabular}{|c|c|c|c|c|c|c|c|}
\hline & RM1 & LMPI & DLCPI & $\mathrm{RP}$ & LEXCH & \multicolumn{2}{|c|}{ TREND } \\
\hline$\beta_{1}$ & $\begin{array}{c}-0.007 \\
{[-2.58]}\end{array}$ & $\begin{array}{l}0.01 \\
{[2.97]}\end{array}$ & 0 & 1 & 0 & \multicolumn{2}{|c|}{0} \\
\hline$\beta_{2}$ & $\begin{array}{l}-0.16 \\
{[-18.98]}\end{array}$ & 0 & 1 & 0 & $\begin{array}{l}-0.05 \\
{[-8.09]}\end{array}$ & \multicolumn{2}{|c|}{$\begin{array}{c}0.0013 \\
{[18.03]}\end{array}$} \\
\hline \multirow{2}{*}{\multicolumn{2}{|c|}{$\beta_{3}$}} & $\begin{array}{l}-0.11 \\
{[-2.46]}\end{array}$ & 0 & 0 & $\begin{array}{l}0.21 \\
{[5.67]} \\
\end{array}$ & $\begin{array}{r}-0 . \\
{[-2} \\
\end{array}$ & $\begin{array}{l}077 \\
.89]\end{array}$ \\
\hline & & \multicolumn{2}{|c|}{$\alpha_{1}$} & & $\alpha_{2}$ & & $\alpha_{3}$ \\
\hline \multicolumn{2}{|c|}{ DRM1 } & \multicolumn{2}{|c|}{$\begin{array}{l}-0.13 \\
{[-0.13]}\end{array}$} & & $\begin{array}{l}0.91 \\
{[0.97]}\end{array}$ & & $\begin{array}{l}-0.71 \\
{[-4.96]}\end{array}$ \\
\hline \multicolumn{2}{|c|}{ DLMPI } & \multicolumn{2}{|c|}{0} & & 0 & & 0 \\
\hline \multicolumn{2}{|c|}{ DDLCPI } & \multicolumn{2}{|c|}{$\begin{array}{l}0.39 \\
{[2.35]}\end{array}$} & & $\begin{array}{l}-1.00 \\
{[-6.45]}\end{array}$ & & $\begin{array}{l}-0.15 \\
{[-6.26]}\end{array}$ \\
\hline \multicolumn{2}{|c|}{ DRP } & \multicolumn{2}{|c|}{$\begin{array}{l}-0.13 \\
{[-13.70]}\end{array}$} & & $\begin{array}{l}0.003 \\
{[0.38]}\end{array}$ & & $\begin{array}{c}0.0002 \\
{[0.17]}\end{array}$ \\
\hline \multicolumn{2}{|c|}{ DLEXCH } & \multicolumn{2}{|c|}{$\begin{array}{l}0.47 \\
{[0.37]} \\
\end{array}$} & & $\begin{array}{l}3.84 \\
{[3.26]}\end{array}$ & & $\begin{array}{l}0.41 \\
{[2.25]}\end{array}$ \\
\hline \multicolumn{2}{|c|}{ Table 6: } & An overic & lentifying & lor & run stru & ure & [t-values \\
\hline
\end{tabular}

Thus, the first long-run relationship qualifies as a type of interest rate policy function in which interest rates react positively to real money and negatively to output:

$$
R P=0.007 \times R M 1-0.01 \times L M P I
$$

From the adjustment coefficients, the interest rate significantly responds to this long-run relationship. An overidentifying test that inverse velocity holds is accepted with a p-value of 0.16 . In such a scenario, interest rates would be raised, if real money growth exceeds output growth. Secondly, we obtain the following inflation adjustment equation, in which there is inflationary pressure in the economy arising from higher real money balances and the trend-adjusted depreciation of the exchange rate:

$$
D L C P I=0.16 \times R M 1+(0.05 \times L E X C H-0.0013 \times \text { trend })
$$

We observe the usual exchange rate channel, in which depreciation increases domestic exports and aggregate output that subsequently feeds back into inflationary pressure. One possible reason for including the trend on the exchange rate is that the nominal exchange rate was out of line with fundamental factors. Therefore, we use a time trend that potentially picks up the exceptional adjustment of the misaligned exchange rate after the crisis. In addition, besides the sensitivity of the inflation rate to this long-run relationship, the exchange rate reacts positively to an out-ofequilibrium of the inflation adjustment equation.

The third cointegrating relationship corresponds to a money demand function in which real money responds positively to the output gap and negatively to the exchange rate:

$$
R M 1=(0.11 \times L M P I-0.0077 \times \text { trend })-0.21 \times L E X C H
$$

The effect of the output gap on real money supply relates to the transaction motive for money holdings whereas the exchange rate effect could be characterized as the opportunity cost of holding 
money. ${ }^{18}$ We could potentially rationalize this finding by arguing that the exchange rate is proxying current expectation of future macroeconomic imbalances or uncertainties so that the central bank uses monetary tools to correct for that. In other words, the exchange rate could be a leading indicator for macroeconomic variables.

From the adjustment coefficients, we observe that real money and inflation react negatively to the money demand equation whereas the exchange rate positively. The positive effect of the exchange rate is intuitive because excess money supply causes depreciation whereas the inflation effect is counterintuitive. It could be possibly explained from the fact that Thai inflation rates have fallen during the Thai recession after the crisis when the central bank attempted to ease the money supply in order stimulate the economy.

\section{$5 \quad$ Full Sample Models}

We focused substantial initial efforts on the full sample model and how to build a well-specified model in terms of misspecification tests and especially parameter stability. Specifically, we estimated different versions of a partial model (Johansen, 1992). By conditioning the endogenous variables on some exogenous variables we hope to capture the very large residuals associated with the crisis. In other words, all the noise and volatility of the crisis period in 1997 is contained in the exogenous variables. In a way, they substitute for employing numerous dummy variables.

We also estimated a linear broken trend model along the lines of Johansen et al (2000). The intuition is that the exchange rate system in Thailand moved from a fixed regime to a floating regime so we might think of the crisis break as a linear trend that has been broken.

\subsection{Model 1: Conditioning on the exchange rate}

The intuition for exogenizing the exchange rate in the full sample model is that the exchange rate forms the predominant volatility in the crisis period so conditioning on it helps to contain statistical problems from that variable such as autocorrelation and normality issues. There are some significant problems with normality and autocorrelation in this partial model. Individually, normality for the interest rate and output can be strongly rejected whereas their individual autocorrelations seem fine. In addition, the interest rate does not pass the individual ARCH and heteroscedasticity tests. Chow tests indicate that the interest rate is unstable around the crisis period.

An interesting exercise for testing the stability of the model is to calculate the recursively calculated components of the trace statistic. We know that the cointegrating rank changes from the pre-crisis to the post-crisis model. Figure 2 shows that the partial model which conditions on the exchange rate has no stable cointegrating rank. Inspecting the bottom graph which excludes the short run fluctuations we see that the ranks jumps from $r=2$ to $r=3$ shortly after the devaluation of the baht.

\footnotetext{
${ }^{18}$ We could not find any net interest rate spread between the interest rate and the exchange rate as a potential building block for the money demand cointegrating relationship.
} 

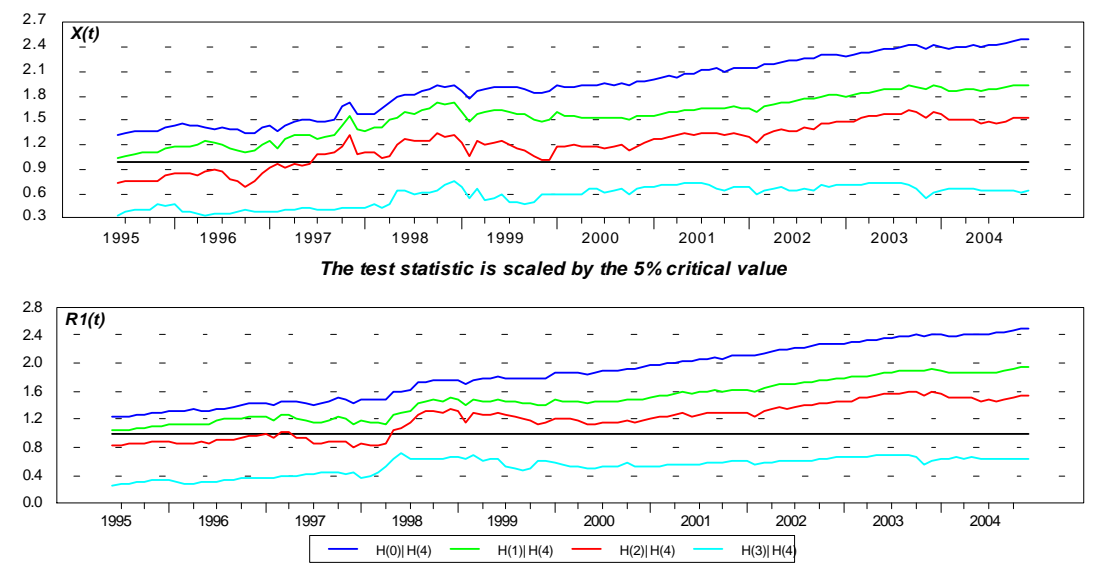

Figure 2: Recursively estimated trace test based on 75 initial observations

In an alternative partial model, we used as a second exogenous variable Thai bank lending with the underlying reason that Thai bank lending growth could qualify as the variable that might explain the structural shift during the crisis period and measure the jump from one equilibrium pre-crisis to the second equilibrium post-crisis. In other words, bank lending could be thought as a proxy for overinvestment in the pre-crisis period, capturing the importance of the investment boom and bust argument by Warr and Vines (2003). This reasoning is plausible since most Thai investment relied on bank-based funding rather than capital markets. But this model is not stable as well. ${ }^{19}$

As discussed before, Thailand suffered a serious current account deficit in the pre-crisis period which was often seen as a contributing factor for the worsening economy before the Asian Crisis. We also attempted to include a current account variable as an exogenous variable into the model in various combinations with the exchange rate and banking lending but no stable and well-specified VAR model could be obtained. Finally, partial models with a PPP relation as one of the exogenous variables were not successful as well.

\subsection{Model 2: Broken linear trend model}

Johansen et al (2000) analyze the cointegrated VAR model subject to structural breaks in the trend. The break points are known, and the trend is linear but piecewise. In general, a cointegrated VAR model for each subsample is estimated in which the parameters are the same for all subsamples except the deterministic trend component which could potentially be different.

Tests for misspecification indicate the strong presence of autocorrelation in the exchange rate. Also, 1-step and breakpoint Chow tests in figure 3 provide evidence that the exchange rate faces a structural break in the broken linear trend model. The problem with this model is that we endogenize the exchange rate so the model suffers from the noise and volatility of that variable around the crisis period.

\footnotetext{
${ }^{19}$ Instead of nominal banking lending which is a stock variable we also used the inflation adjusted banking lending growth rate as an exogenous variable but the full sample 17 odel remained unstable.
} 

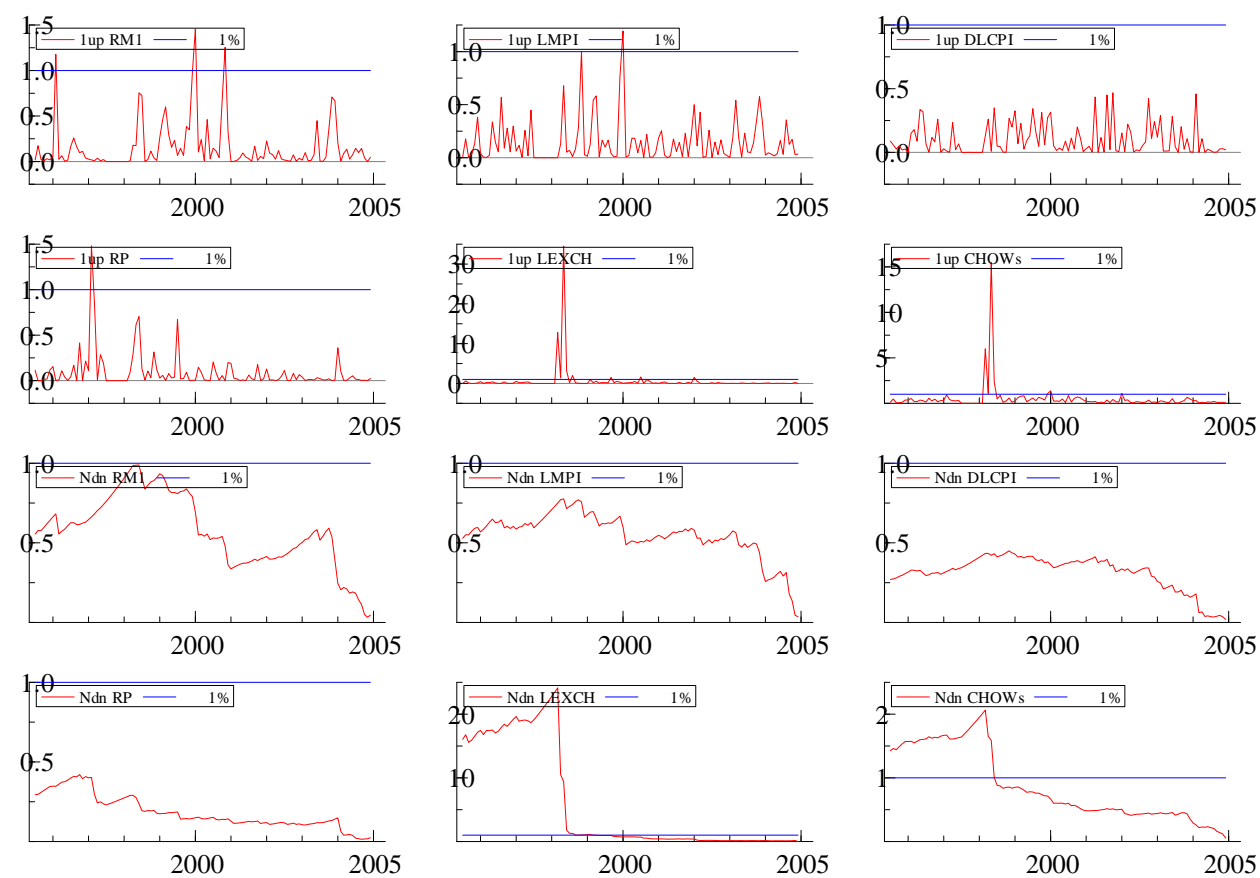

Figure 3: 1-step and breakpoint Chow tests in broken linear trend model

To conclude, we did not manage to fit a well-specified cointegrated VAR model through the crisis period. The bottomline is that our subsample technique is superior in investigating the dynamics in the VAR model and giving some information about how some channels of the Thai monetary transmission mechanism work. The findings support our argument in section 2 that many structural VAR models about Thailand are misspecified especially when fitting a model through the crisis. Among them are studies by Hirunraengchok (2004), Song (2002) and Disyatat and Vongsinsirikul (2003). In contrast, it supports the underlying reasoning of Patrawimolpon et al (2001) and Fung (2002) of a subsample-based analysis.

\section{Short- Run Dynamics: Identification of common driving trends}

In this section we will informally describe the moving average (MA) representation of the cointegrated VAR model because it helps us to understand the common stochastic trends (permanent shocks) and the transitory shocks in the model (see Juselius, 2004, for a formal analysis). Specifically, we impose restrictions on the common trends. Our primary interest is how permanent shocks to the system permeate on the system variables especially the endogenous variables of interest. This exercise gives us some indication of the monetary transmission mechanism in Thailand insofar as we are able to gauge the effects of monetary policy shocks to the economy.

In general, in the Granger-Johansen representation, the $C$ matrix (see Juselius, 2004) contains important information how variables are affected by the stochastic driving trends in the system. For example, the columns of the $C$ matrix indicate how the cumulated shocks to any individual 
VAR equations feed into each of the endogenous variables. In contrast, a row wise inspection provides information of the weights of the cumulated shocks for each variable.

Table 7 reports the $C$ matrix based on both the restricted $\alpha$ and $\beta$ for the pre-crisis model, that is, we have imposed our two cointegrating relationships and the weak exogeneity of $R M 1, R P$ and $L E X C H$. Thus, the columns of $\hat{\varepsilon}_{L M P I}$ and $\hat{\varepsilon}_{D L C P I}$ have been set to zero.

\begin{tabular}{ccccccc}
\hline \hline & $\hat{\varepsilon}_{R M 1}$ & $\hat{\varepsilon}_{L M P I}$ & $\hat{\varepsilon}_{D L C P I}$ & $\hat{\varepsilon}_{R P}$ & $\hat{\varepsilon}_{L E X C H}$ & trend \\
\hline RM1 & 0.88 & 0 & 0 & -0.62 & -0.36 & 0.0059 \\
& {$[10.89]$} & & & {$[-0.23]$} & {$[-0.71]$} & \\
LMPI & -0.01 & 0 & 0 & -1.26 & -1.00 & 0.0064 \\
& {$[-0.03]$} & & & {$[-2.18]$} & {$[-9.20]$} & \\
DLCPI & 0.01 & 0 & 0 & 0.01 & 0.01 & -0.00 \\
& {$[10.83]$} & & & {$[0.23]$} & {$[1.25]$} & \\
RP & -0.01 & 0 & 0 & 1.00 & -0.02 & 0.00 \\
& {$[-1.29]$} & & & {$[7.83]$} & {$[-0.64]$} & \\
LEXCH & 0.01 & 0 & 0 & -0.46 & 1.11 & 0.0003 \\
& {$[0.45]$} & & & {$[-0.38]$} & {$[8.38]$} & \\
\hline
\end{tabular}

Table 7: The pre-crisis MA impact matrix, restricted $\alpha$ and $\beta$

Restricting the $C$ matrix, we observe from the t-values that shocks to money have not any permanent effects on output because the null hypothesis of a zero effect cannot be rejected. Furthermore, there is strong indication that positive shocks to money increase the inflation rate and money itself permanently which suggest that money shocks are an important pushing force of our cointegrated VAR model. Also from an inspection of the two remaining weakly exogenous variables $R P$ and $L E X C H$, we detect the expected negative effect of interest rate shocks to output and the negative effect of exchange rate shocks to output as discussed before.

Analyzing the $C$ matrix row-wise reveals that firstly, output is predominantly influenced by shocks to the interest rate and the exchange rate, and that secondly, the inflation rate's predominant influence is empirical shocks to money.

Overall, the above findings are consistent with the results from section 4 . Specifically, the three weakly exogenous variables $R M 1, R P$ and $L E X C H$ are the significant pushing forces in our model, and in contrast, the forces that pull back the system to equilibrium are represented by the equilibrium adjustment mechanism in the equations for output and the inflation rate.

For the post-crisis model, we observe that positive shocks to output have permanent effects on money, own output and inflation. The permanent effect on money suggests that money accommodates the increase in output, potentially through higher transaction demand for real money holdings. Note that this result is consistent with the money demand cointegrating relationship in which we observed a positive long-run effect from output to money. Further, the positive relation between output and inflation is economically intuitive, that is, shocks to output put pressure on prices.

In addition, there is evidence that shocks to the cumulated residuals of money and the interest rate are only transitory in character. This complies with our previous findings in section 4 where we found significant adjustment coefficients in $\alpha$ for both variables. Also note that there is some weak evidence that inflation shocks at least influence two system variables permanently: Money and the exchange rate. The negative effect on money potentially implies that monetary policy is counteracting the effects of positive inflation shocks. 
We recall that we rejected weak exogeneity for the exchange rate in section 4 but we argued from its insignificant adjustment coefficients $\alpha$ that the exchange rate will not be a normalizing variable in the subsequent identification of the $\beta$. Our line of argumentation is consistent insofar because shocks to the exchange rate have permanent effects on money, the inflation rate and the exchange rate itself. The effect on inflation is positive whereas exchange rate shocks contract money holdings. In other words, the result might suggest that the central bank would counteract inflationary tendencies by contracting money following a depreciation.

\section{Conclusion and Possible Extensions}

We attempted to analyze monetary policy and the monetary transmission mechanism in the Thai economy based on a well-specified cointegrated VAR approach. Our findings reveal that any full sample modeling strategy that incorporates the Asian Crisis will be misspecified, and policy inferences from such a model are potentially invalid. Our subsample-based modeling strategy is able to account for the effects of the structural break and pinpoint the fundamental differences in both the pre-crisis and post-crisis model.

Specifically, we find that Thai monetary policy was potentially immobilized in the pre-crisis period by virtue of the pegged exchange rate regime and the financial liberalization of the Thai economy. Many existing studies that investigate the monetary transmission mechanisms in Thailand do not take account of this fact and make assumptions of the monetary policy stance of the Thai central bank in this period. For example, Patrawimolpon et al (2001) assume that the central bank either targets money supply or the interest rate in their pre-crisis model. Such assumptions are potentially invalid insofar because they are at odds with the typical Mundell-Fleming type argument of the inconsistency of the trinity independent monetary policy, fixed exchange rate regime and open capital account. Analogous to the above argumentation, we do not obtain an interest rate policy function.

Our two cointegrating vectors in the pre-crisis model correspond to an inflation adjustment equation and IS-type equation. Similarly to Bhanthumnavin (2002), we cannot obtain a Phillips Curve relationship. Inflation seems foremost a monetary phenomenon and is positively related to the inverse velocity of money.

Our results for the pre-crisis monetary transmission mechanism are consistent with the identification of the common stochastic trends. In details, money shocks have permanent effects on inflation but only transitory effects on output. The transitory response of output supports the reasoning of Corbett and Vines (1999) and Phongpaichit and Baker (2002) that the monetary tightening of the Thai central bank in 1993-4 to cool down the economy was ineffective because financial intermediaries were able to borrow abroad at cheaper interest rates. Also, there is no channel from monetary shocks to the exchange rate which is economically intuitive. Shocks to the interest rates significantly influence output which we attributed to a possible financial accelerator argument (Bernanke et al, 1996) or the fact that domestic interest rates move with foreign interest rates which were not included in the model.

In the post-crisis model, we do find a money demand equation in which money supply is 
determined by the output gap and the exchange rate which could proxy as the opportunity cost of holding money. One potential explanation could be that the exchange rate is proxying current expectation of future macroeconomic imbalances or uncertainties so that the central bank uses monetary tools to correct for that. Of course, the type of money demand is subject to the included system variables. Further, we obtain an interest rate policy and inflation adjustment equation. In general, we find it very difficult to explain the short run behaviour of the exchange rate by fundamental factors which complies with the arguments of Meese and Rogoff (1983).

What is the bottomline of the paper? We still do not know the full monetary transmission mechanism of money shocks to the economy, although we could disentangle various components. The question is 'What is the black box?' to borrow the terminology of Bernanke and Gertler (1995). To answer the questions, we could extend the model with further macroeconomic variables such as investment, stock market and bank lending data in order to obtain a full picture how monetary policy shocks are transmitted to the economy through the asset price and credit channels. For instance, Disyatat and Vongsinsirikul (2003) add these additional variables individually to a small (three variable) VAR model. Their approach is problematic because they do not deal with nonstationarity so any findings will be potentially biased if equations are estimated in levels.

We anticipate that it will be a difficult task to incorporate these variables into the cointegrated VAR framework. The structural break of the Asian Crisis complicates such an extended study. Also, we might lose tractability of the model if the dimension rapidly increases, an argument which Juselius (2007) elaborates on. This is surely a limitation of our VAR approach because the economy is an interrelated dynamic system in which many factors influence the key macroeconomic indicators. Our initial aim has been modest because data issues and the Asian Crisis made it very difficult to decompose the short- run dynamics of the system variables.

From a policy viewpoint, we see scope for further improvements of the cointegrated VAR modelling approach in order to draw sensible statistical inferences. For instance, the literature on forecasting in a nonstationary world (Clements and Hendry, 1999) becomes relevant. But a forecasting exercise would be rather limited because forecasts of the pre-crisis model will suffer from the structural break in 1997.

Another interesting forecasting exercise would be to estimate a full sample cointegrated VAR model and analyze the factors that significantly contribute to the forecast failure of the Asian Crisis. We potentially could adopt the methodology of Clements and Hendry (1999) who provide a taxonomy of forecast errors in varying macroeconomic settings. According to their framework, deterministic shifts are usually the primary determinant of forecast failure. But we know from the estimation of the broken linear trend model by Johansen et al (2000) that a deterministic trend is not able to potentially overcome the structural break during the Asian Crisis. Therefore, possible different explanations for the forecast failure would provide a valuable addition to our reasoning in section 5 to account for the differences in the pre- and post-crisis period.

An issue which is often neglected in related studies is the quality of the data. We argued before that Thailand faces some data problems in terms of the availability of monthly frequencies for GDP. The manufacturing production index (MPI) that we adopt can only imperfectly qualify for measuring the movements of GDP. 
Finally, our results could be potentially adopted to different country experiences in South East Asia that had fixed exchange rate regimes and were affected by the Asian Crisis. Supposedly, many South East Asian countries liberalized their financial markets in the early 1990s, and therefore there might be cross-country similarities between the monetary transmission mechanisms and the degree of effectiveness of monetary policy. For instance, Fung (2002) attempted to explain these in a structural VAR setting. Our cointegrated VAR methodology could provide an alternative to answer such questions. 


\section{References}

Agenor, P.R., M. Miller, D. Vines and A. Weber (1999) ed. The Asian Financial Crisis: Causes, Contagion and Consequences. Cambridge University Press: Cambridge

Baqir, R. (2002) "The channels of monetary policy transmission in Thailand," in Thailand: Selected Issues and Statistical Appendix, Country Report No. 02/195, IMF

Bayoumi, T. and Morsink, J.(2001) "A Peek Inside the Black Box: The Monetary Transmission Mechanism in Japan," IMF Staff Papers, 48(1), 22-57

Bernanke, B. and M. Gertler (1995), "Inside the black box: The credit channel of monetary transmission mechanism, "Journal of Economic Perspectives, 9, 4, 27-28

Bernanke, B., M. Gertler and S. Gilchrist (1996) 'The Financial Accelerator and the Flight to Quality," The Review of Economics and Statistics, 78(1),1-15

Bernanke, B. and I. Mihov (1998) 'The liquidity effect and long-run neutrality,' Carnegie-Rochester Conference on Public Policy, 49, 149-194

Beyer, A. (1999) 'Monetary transmission mechanism in Germany: Evidence from a structural econometric model,' Discussion Papers 98-05, Institute of Economics, University of Copenhagen.

Bhanthumnavin, K. (2002) 'The Phillips curve in Thailand,' Department of Economics, University of Oxford, Gorman Workshop Series

Chowdhury, A (1997) 'The financial structure and the demand for money in Thailand', Applied Economics, 29, 401-409

Christiano, L. , Eichenbaum, M. and C. Evans (1999) 'Monetary Policy Shocks: What Have We Learned and to What End?' in Taylor and Woodford, Handbook of Macroeconomics

Clements, M.P. and D.F. Hendry (1999) Forecasting Non-stationary Economic Time Series. Cambridge, Mass.: MIT Press

Corbett, J. and D. Vines (1999) 'Asian Currency and Financial Crises: Lessons from Vulnerability, Crisis and Collapse,' The World Economy, 22(2), 155-77

Disyatat, P. and P. Vongsinsirikul (2003) 'Monetary Policy and the Transmission Mechanism in Thailand', Journal of Asian Economics, 14, 389-418

Doornik, J.A., D.F. Hendry and B. Nielsen (1996) 'Inference in cointegrating models: UK M1 revisited,' Journal of Economic Surveys, 12, 5, 533-572

Fung, B. (2002) 'A VAR analysis of the effects of monetary policy in East Asia,' Bank for International Settlements, BIS Working Paper No.119

Hirunraengchok, A. (2004) 'Structural Vector Autoregressions: The Case of Thailand', Macro Office, National Economic and Social Development Board, Working Paper

Irwin, G. and D. Vines (2003) 'Government guarantees, investment and vulnerability to financial crises,' Review of International Economics, 11(5), 860-74 
Johansen, S. (1988) 'Statistical analysis of cointegration vectors,' Journal of Economic Dynamics and Control, 12,231-254

Johansen, S. (1992) 'Testing weak exogeneity and the order of cointegration in UK money demand data,' Journal of Policy Modelling, 14, 313-335

Johansen, S. (1995) Likelihood- based inference in cointegrated vector auto-regressive models. Oxford University Press: Oxford

Johansen, S., R. Mosconi and B.Nielsen (2000) 'Cointegration analysis in the presence of structural breaks in the deterministic trend,' Econometrics Journal, 3, 216-249

Juselius, K (1996) 'An empirical analysis of the changing role of German Bundesbank after 1983, Oxford Bulletin of Economics and Statistics, 58, 791-817

Juselius, K. (2007) The Cointegrated VAR model: Methodology and Applications. Oxford University Press: Oxford

Kasajima, S. and S. Lewis 'Equilibrium real exchange rate, real exchange rate misalignment, and the current account: An econometric analysis of Thailand's experience in Restructuring Asian Economics for the New Millennium, Vol 9A, 281-322

Krugman, P. (1999) 'Balance Sheets, the transfer problem, and financial crises' International Tax and Public Finance, 6, 459-72

Masih, A. and Masih, R. (1996)' Empirical tests to discern the dynamic causal chain in macroeconomic activity: New evidence from Thailand and Malaysia based on a multivariate cointegration/VECM approach', Journal of Policy Modeling, 18(5), 531-560

Masson, P. (1999) 'Contagion: Monsoonal effects, spillovers, and jumps between multiple equilibria,' Journal of International Money and Finance, 18, 587-602

Meese, R. A. and K. Rogoff (1983) 'Empirical exchange rate models of the seventies: Do they fit out of sample?' Journal of International Economics, 14, 3-24

Mishkin, F. (1995) "Symposium on the Monetary Transmission Mechanism," Journal of Economic Perspectives, 9(4), 3-10

Phongpaichit, P. and C. Baker (2002) Thailand: Economy and Politics, Second Edition. Oxford University Press: Oxford

Patrawimolpon, P., Rattanalankar, T., Charumilind, C and P. Ngamchant (2001) ' A Structural Vector Autoregressive Model of Thailand: A Test for Structural Shifts, ' Bank of Thailand, Monetary Policy Group (Bangkok)

Pesaran, M.H. and R.P. Smith (1998) 'Structural Analysis of Cointegrating VARs,' Journal of Economic Surveys, 12(5), 471-505

Song, J.H. (2002) ' Shocks and Responses: Re-evaluating monetary policy of Thailand during the currency crisis', Department of Economics, University of Chicago, mimeo

Warr, P. (1998) 'Thailand,' chapter 3 in McLeod, R. and R. Garnaut (ed.), East Asia in Crisis. Routledge: London

Warr, P. and D. Vines (2003) 'Thailand's investment-driven boom and crisis,' Oxford Economic Papers, 55, 440-466 